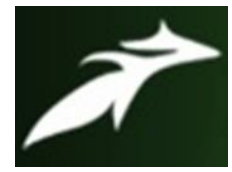

Balakesava Reddy. J et al, International Journal of Advances in Agricultural Science and Technology,

Vol.7 Issue.11, November-2020, pg. 16-20

ISSN: 2348-1358

Impact Factor: 6.057

NAAS Rating: 3.77

\title{
In Vitro Evaluation of Paddy Straw Treated with Maize Spent Liquor at Varying Levels and Different Days of Incubation
}

\author{
Balakesava Reddy. $\mathbf{J}^{1}$; Raja Kishore. $\mathrm{K}^{2 *}$; Srinivas Kumar. $\mathbf{D}^{3}$; Asha Latha. $\mathbf{P}^{4}$ \\ ${ }^{1}$ Post Graduate Student, Department of Animal Nutrition \\ ${ }^{2}$ Assistant Professor, Department of Animal Nutrition \\ ${ }^{3}$ Professor and Head, Department of Animal Nutrition \\ ${ }^{4}$ Associate Professor, Department of Livestock Production and Management \\ NTR College of Veterinary Science, Gannavaram \\ Sri Venkateswara Veterinary University, Tirupati, Andhra Pradesh, India \\ *Corresponding Author's Email- dr rajakishore@yahoo.co.in \\ DOI: 10.47856/ijaast.2020.v07i11.003
}

\begin{abstract}
An experiment was conducted to evaluate paddy straw treated with maize spent liquor (MSL) at 10, 20 and $30 \%$ and subjected to different days $(1,2,3,4$ and 5) of incubation for in vitro digestibility of nutrients. Chemical composition of MSL reported to contain 16.88, 91.96, 8.04, 14.33, 4.37, 0.00, 73.26, 0.24 and 0.69 percent DM, OM, TA, $\mathrm{CP}, \mathrm{EE}, \mathrm{CF}, \mathrm{NFE}$, calcium and phosphorus, respectively. Data revealed that in vitro digestibility (\%) of dry matter, organic matter and crude protein of paddy straw treated with MSL at 10 and 20\% increased linearly (p>0.05) from 1 to 5 days of incubation, respectively, but decreased at 30\% level of inclusion. Higher in vitro digestibility (\%) of dry matter (50.10), organic matter (52.99) and crude protein (14.97) were observed in paddy straw treated with 20\% MSL and incubated for one day compared to other treatments. It is concluded that better in vitro digestibility of nutrients were observed in paddy straw treated with MSL at $20 \%$ level and incubated for one day.
\end{abstract}

Keywords: In vitro digestibility, Paddy straw, Maize spent liquor

\section{Introduction}

Maize spent liquor is a liquid by-product containing condensed steeped water and distillers soluble from a wet corn milling plant. It is a viscous brown colour liquid consisting of water-soluble extracts of corn with sweet odour and acidic $\mathrm{pH}$ (Filipovic et al., 2002). It is rich in crude protein, amino acids, 2 minerals, vitamins, reducing sugars, organic acids mainly lactic acid (20-25\%), enzymes and other nutrients; and it is free from fat, fibre, silica and anti-nutritional factors (Talpada et al., 1987). This makes it an excellent nutritive source as animal feed and also as an efficient nutrient supplement for microbial fermentation (Chovatiya et al., 2011). However, the sulphur amino acid content of MSL is about $2.43 \%$, though it is deficient in lysine $(0.73 \%)$. It is reported that MSL have been used as liquid feed supplement for post weaning lambs (Mirza and Mushtaq, 2006); beef cattle (White and Johnson, 2003) and buffalo bulls (Aparna et al., 2013) without any adverse effects. On the other hand, direct feeding of corn by-products to productive animals resulted in polio encephalomalacia due to high sulphur content (Lardy, 2014) and reproductive disorders due to mineral imbalance. This feature led to the limited utilization of MSL as a sole feed for livestock.

Paddy straw is a major agro-residue fed to ruminants in India. It contains $25-45 \%$ cellulose, 25-30\% hemi-cellulose and 10-15\% lignin with low nitrogen, vitamins and minerals. Further, the high quantities of silica in paddy straw will hinder the nutrient availability to rumen microbes and eventually limits the necessary nutrient uptake for a satisfactory performance of the animal (Ganai et al., 2006). Various processing methods are in vogue for improving the nutritive value of paddy straw and one such method is utilization of maize spent liquor (MSL) or corn steep liquor (CSL) from the corn wet milling plants. Despite the improvements of crop residues using various agro-industrial by-products, the efficient utilization to the desirable extent is still awaited. 


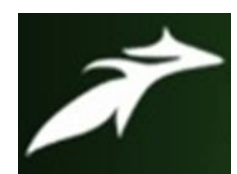

Balakesava Reddy. J et al, International Journal of Advances in Agricultural Science and Technology, Vol.7 Issue.11, November-2020, pg. 16-20

In view of the above problems, it would be ideal if MSL could be used as a supplement for improving the nutritive value of paddy straw instead of as a sole feed. However, very little research data is available regarding the optimum level of inclusion of MSL for improved digestibility of nutrients in straws. Hence, the present study was conducted to arrive at the optimum level of MSL to be used and days of incubation for obtaining the better digestibility of nutrients through in vitro studies.

\section{Materials and Methods}

The present work was carried out at Department of Animal Nutrition, NTR College of Veterinary Science, Gannavaram, MSL is procured from Paramesu Biotech Pvt. Ltd., Devarapalli (V), West Godavari District, Andhra Pradesh. The three different concentrations of MLS were prepared i.e. 10\% MSL (50 ml MSL in $450 \mathrm{ml}$ of water), $20 \% \mathrm{MSL}(100 \mathrm{ml} \mathrm{MSL}$ in $400 \mathrm{ml}$ of water) and 30\% MSL (150 ml MSL in $350 \mathrm{ml}$ of water). Paddy straw was ground through a medium mesh $(1 \mathrm{~mm})$ screen in a Weily mill. Ground paddy straw of about 500g was taken into three separate trays and diluted MSL i.e., 10, 20 and 30 per cent is sprayed uniformly over paddy straw in each tray. Then paddy straw is mixed with MSL solution thoroughly by hand for uniform distribution. The treated paddy straw from each tray was divided into five portions (200 gm each) and was taken into polythene covers, sealed air tightly and incubated for different days (1, 2, 3, 4 and 5). Chemical composition (AOAC, 2007) and forage fibre constituents (Van Soest et al., 1991) of paddy straw and MSL were analyzed. Calcium and phosphorus of paddy straw and MSL were analyzed as per the procedure of Talapatra et al. (1940) The paddy straw treated with MSL (10, 20 and 30\%) and subjected to different days (1, 2, 3, 4 and 5) of incubation was analysed for in vitro dry matter, organic matter and crude protein digestibility (Tilley and Terry, 1963). The data was analysed statistically (Snedecor and Cochran, 1994).

\section{Results and Discussion}

The chemical composition of paddy straw and MSL was presented in Table 1. The DM content of maize spent liquor (MSL) used for treating of paddy straw in the present study was 16.88 per cent. In contrast, Li et al. (2016) and Ullah et al. (2017) reported higher DM values (30.0 to 77.25\%), while Filipovic et al. (2002) reported lower DM content $(5.27 \%)$ as compared to present findings. The CP content of MSL observed in the present study was $14.33 \%$. In contradiction, Malumba et al. (2015) and Azizi- Shotorkhoft et al. (2016) reported higher CP values (21.0 to $48.0 \%$ ) in MSL. On the other hand, the EE (4.37\%) and TA (8.04\%) content of MSL in the present study were lower than the values reported by Malumba et al. (2015). The NFE content of MSL observed in the present study is $73.26 \%$. Further, higher NFE value is reported than the value given by Chovatiya et al. (2011) and Ullah et al. (2017). The CF content of MSL in the present study reported to be zero. Variation in the chemical composition of MSL as reported by different workers might be due to variation in maize composition, geographical distribution, processing methods and storage conditions.

The in vitro digestibility (\%) of DM, OM and CP in paddy straw treated with MSL at 10, 20 and 30 per cent levels and incubated for 1, 2, 3, 4 and 5 days were presented in Tables 2, 3 and 4. The IVDMD (\%) increased ( $p>0.05)$ with increasing levels of MSL up to $20 \%$ and then decreased at $30 \%$ level irrespective of the day of incubation. Further, the in vitro digestibility of DM reduced from 1 to 5 days of incubation in all the treatments and the differences were not statistically significant. Similar pattern was also observed in vitro digestibility of OM and CP in paddy straw treated with 10, 20 and 30 per cent level of MSL and incubated for 1 to 5 days. Puri and Gupta (1998) reported that, urea treatment of paddy straw significantly increased $(\mathrm{p}<0.01)$ in vitro DM digestibility at $40 \%$ moisture level. Similar findings were reported by Malumba et al. (2015). Peripolli et al. (2017) reported that, paddy straw supplemented with mineral and protein-energy supplements (MPES) significantly increased $(\mathrm{p}<0.05)$ in vitro DM and OM digestibility.

The nitrogen content of paddy straw was improved upon addition of MSL was due to high lactic acid content of MSL. However, the provision of readily available nutrients (carbohydrates, minerals and proteins) for proper fermentation by MSL have caused a further drop of $\mathrm{pH}$ in MSL treated paddy straw. Decreased $\mathrm{pH}$ has probably changed free $\mathrm{NH}_{3}$ into an ionic form of ammonia that is very reactive and has a greater tendency to make bonds with fibrous materials (Borhami et al., 1982). This might be the reason for improved digestibility of $\mathrm{DM}, \mathrm{OM}$ and $\mathrm{CP}$ in vitro. 


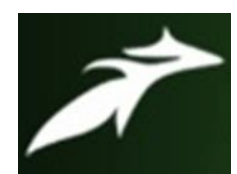

Balakesava Reddy. J et al, International Journal of Advances in Agricultural Science and Technology, Vol.7 Issue.11, November-2020, pg. 16-20

\section{Conclusion}

It was concluded paddy straw treated with 20 per cent level MSL and incubated for one day reported better in vitro digestibility of dry matter, organic matter and crude protein. Further, the data has to be supported by in vivo studies with regard to palatability, intake and digestibility of nutrients and health of animal.

\section{References}

[1] AOAC. 2007. Official methods of Analysis. $18^{\text {th }}$ ed. Association of Official Analytical Chemists. Washington, D.C.

[2] Aparna, R., Rao, E.R., Kumar, D.S. and Rao, S.J., 2013, Dietary inclusion of maize spent liquor on intake and nutrient utilization in buffalo bulls. Indian Journal of Animal Nutrition. 30(3): 224-227.

[3] Azizi- Shotorkhoft, A., Sharifi, A., Mirmohammadi, D., Baluch- Gharaei, H. and Rezaei, J., 2016, Effects of feeding different levels of corn steep liquor on the performance of fattening lambs. Journal of Animal Physiology and Animal Nutrition. 100(1): 109-117.

[4] Borhami, B.E., Sundstol, A.F. and Garmo, T.H., 1982, Studies of ammonia treated straw. Fixation of ammonia treated straw by spraying with acids. Animal Feed Science and Technology. 7: 53-60.

[5] Chovatiya, S.G., Bhatt, S.S. and Shah, A.R., 2011, Evaluation of corn steep liquor as a supplementary feed for Labeo rohita (Ham.) fingerlings. Aquaculture International. 19(1): 1-12.

[6] Filipovic, S.S., Ristic, M.D. and Sakac, M.B., 2002, Technology of Corn Steep Application in Animal Mashes and their Quality. Roum. Biotechnol. Lett. 7(3): 705-710.

[7] Ganai, A.M., Matto, F.A., Singh, P.K., Ahmad, H.A. and Samoon, M.H., 2006, Chemical composition of some feeds, fodders and plane of nutrition of livestock of Kashmir valley. SKUAST Journal of Research. 8: 145-151.

[8] Lardy, G. and Anderson, V., 2014, Feeding Co-products of the Ethanol Industry to Beef Cattle. AS1242, North Dakota State University.

[9] Li, X., Xu, W., Yang, J., Zhao, H., Pan, C., Ding, X. and Zhang, Y., 2016, Effects of applying lactic acid bacteria to the fermentation on a mixture of corn steep liquor and air-dried rice straw. Animal Nutrition. 2(3): 229-233.

[10] Malumba, P., Boudry, C., Roiseux, O., Bindelle, J., Beckers, Y. and Béra, F., 2015, Chemical characterisation and in vitro assessment of the nutritive value of co-products yield from the corn wet-milling process. Food chemistry. 166: 143149.

[11] Mirza, M.A. and Mushtaq, T., 2006, Effect of supplementing different levels of corn steep liquor on the post-weaning growth performance of pak-karakul lambs. Pakistan Veterinary Journal. 26(3): 135-137.

[12] Peripolli, V., Barcellos, J.O.J., Prates, Ê.R., McManus, C., Stella, L.A., Camargo, C.M., Costa Jr, J.B.G. and Bayer, C., 2017, Additives on in vitro ruminal fermentation characteristics of rice straw. Revista Brasileira de Zootecnia 46(3): 240250.

[13] Puri, J.P. and Gupta, B.N., 1998, Effect of Urea Treatment of Rice Straw on Chemical Composition and In vitro Dry Matter Digestibility. Indian Journal of Animal Nutrition. 15(4), 287-289.

[14] Snedecor, C.W and Cochran, W.G., 1994, Statistical methods (6th edition). Iowa State University, Press Anes, USA.

[15] Talapatra, S.K., Ray, S.C. and Sen, K.C. 1940. The analysis of mineral constituents in biological materials. Part-1. Estimation of Phosphorus, chlorine, calcium, magnesium, sodium and potassium in foodstuffs. Indian Journal of Veterinary Science and Animal Husbandry. 10: 243.

[16] Talpada, P.M., Desai, M.C., Desai, H.B., Patel, Z.N. and Shukla, P.C. 1987. Nutritive value of corn steep liquor. Indian Journal of Animal Nutrition. 4(2): 124-125.

[17] Tilley, J.M.A. and Terry, R.A., 1963, A two stage technique for in vitro digestion. Journal of British Grassland Society. 18:104.

[18] Ullah, Z., Yousaf, M., Shami, M.M., Sharif, M. and Mahrose, K., 2017, Effect of graded levels of dietary corn steep liquor on growth performance, nutrient digestibility, haematology and histopathology of broilers. Journal of Animal Physiology and Animal Nutrition. 102(1): 1-8.

[19] White, P.J. and Johnson, L.A., 2003, Corn: Chemistry and Technology, American Association of Cereal Chemists. Inc., St. Paul, MN, 467-468. 


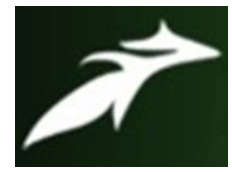

Balakesava Reddy. J et al, International Journal of Advances in Agricultural Science and Technology, Vol.7 Issue.11, November-2020, pg. 16-20

ISSN: 2348-1358

Impact Factor: 6.057

NAAS Rating: 3.77

Table 1. Chemical composition (on \% DMB) of feed stuffs

\begin{tabular}{lcc}
\hline Nutrient & Paddy straw & Maize Spent Liquor \\
\hline DM & 90.33 & 16.88 \\
OM & 85.60 & 91.96 \\
TA & 14.40 & 8.04 \\
CP & 3.75 & 14.33 \\
EE & 1.54 & 4.37 \\
CF & 36.92 & 0.00 \\
NFE & 43.39 & 73.26 \\
NDF & 76.68 & - \\
ADF & 49.19 & - \\
Hemi-cellulose & 27.48 & - \\
Cellulose & 34.68 & - \\
ADL & 6.42 & - \\
Silica & 4.25 & - \\
Calcium & 0.51 & 0.24 \\
Phosphorus & 0.13 & 0.69 \\
\hline
\end{tabular}

Table 2. In vitro digestibility of DM (\%) in paddy straw treated with MSL at $10 \%, 20 \%$ \& $30 \%$ levels on different days of incubation.

\begin{tabular}{|c|c|c|c|c|}
\hline \multirow{2}{*}{ Day of Incubation } & \multicolumn{3}{|c|}{ MSL Level } & \multirow[b]{2}{*}{$\operatorname{Mean} \pm \mathrm{SE}^{\mathrm{NS}}$} \\
\hline & $10 \%$ & $20 \%$ & $30 \%$ & \\
\hline 1 & $49.03 \pm 2.01$ & $50.10 \pm 1.12$ & $49.93 \pm 1.06$ & $49.68 \pm 0.68$ \\
\hline 2 & $48.88 \pm 1.08$ & $49.77 \pm 0.97$ & $49.65 \pm 0.74$ & $49.43 \pm 0.45$ \\
\hline 3 & $48.45 \pm 1.10$ & $49.50 \pm 0.72$ & $49.38 \pm 0.95$ & $49.11 \pm 0.47$ \\
\hline 4 & $47.68 \pm 2.62$ & $48.93 \pm 0.98$ & $48.54 \pm 0.98$ & $48.38 \pm 0.80$ \\
\hline 5 & $47.52 \pm 1.27$ & $48.66 \pm 0.80$ & $48.41 \pm 1.37$ & $48.20 \pm 0.57$ \\
\hline $\operatorname{Mean} \pm \mathrm{SE}^{\mathrm{NS}}$ & $48.31 \pm 0.61$ & $49.39 \pm 0.36$ & $49.18 \pm 0.40$ & \\
\hline
\end{tabular}

$\sqrt{S}$ - Non-significant 


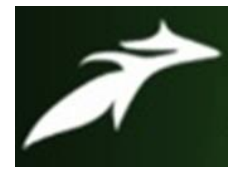

Balakesava Reddy. J et al, International Journal of Advances in Agricultural Science and Technology, Vol.7 Issue.11, November-2020, pg. 16-20

ISSN: 2348-1358

Impact Factor: 6.057

NAAS Rating: 3.77

Table 3. In vitro digestibility of OM (\%) in paddy straw treated with MSL at $10 \%, 20 \%$ \& $30 \%$ levels on different days of incubation.

\begin{tabular}{ccccc}
\hline \multirow{2}{*}{ Day of Incubation } & \multicolumn{4}{c}{ MSL Level } \\
\cline { 2 - 5 } & $\mathbf{1 0 \%}$ & $\mathbf{2 0 \%}$ & $\mathbf{3 0 \%}$ & Mean $\pm \mathbf{S E}^{\mathbf{N S}}$ \\
\hline 1 & $52.12 \pm 1.08$ & $52.99 \pm 0.94$ & $52.62 \pm 1.05$ & $52.57 \pm 0.48$ \\
2 & $51.97 \pm 1.06$ & $52.73 \pm 0.89$ & $52.49 \pm 0.91$ & $52.39 \pm 0.45$ \\
3 & $51.25 \pm 1.64$ & $52.64 \pm 1.16$ & $52.24 \pm 1.01$ & $52.04 \pm 0.64$ \\
4 & $50.84 \pm 1.59$ & $51.76 \pm 0.80$ & $51.55 \pm 1.03$ & $51.38 \pm 0.56$ \\
5 & $50.50 \pm 1.76$ & $51.25 \pm 0.31$ & $51.03 \pm 0.82$ & $50.93 \pm 0.52$ \\
Mean $\pm \mathbf{S E}^{\mathrm{NS}}$ & $51.33 \pm 0.53$ & $52.27 \pm 0.36$ & $51.98 \pm 0.38$ & \\
\hline
\end{tabular}

- Non-significant

Table 4. In vitro digestibility of CP (\%) in paddy straw treated with MSL at $10 \%, 20 \%$ \& $30 \%$ levels on different days of incubation.

\begin{tabular}{ccccc}
\hline \multirow{2}{*}{ Day of Incubation } & \multicolumn{4}{c}{ MSL Level } \\
\cline { 2 - 5 } & $\mathbf{1 0 \%}$ & $\mathbf{2 0 \%}$ & $\mathbf{3 0 \%}$ & Mean $\pm \mathbf{S E}^{\mathbf{N S}}$ \\
\hline 1 & $14.26 \pm 1.00$ & $14.97 \pm 1.28$ & $14.81 \pm 0.83$ & $14.68 \pm 0.49$ \\
2 & $14.12 \pm 1.54$ & $14.94 \pm 0.93$ & $14.62 \pm 0.73$ & $14.56 \pm 0.52$ \\
3 & $13.68 \pm 0.96$ & $14.64 \pm 1.23$ & $14.48 \pm 0.80$ & $14.26 \pm 0.49$ \\
4 & $12.65 \pm 0.40$ & $14.15 \pm 1.15$ & $13.97 \pm 0.41$ & $13.59 \pm 0.44$ \\
5 & $12.40 \pm 0.84$ & $13.55 \pm 0.99$ & $13.41 \pm 0.58$ & $13.12 \pm 0.43$ \\
Mean $\pm \mathbf{S E}^{\mathrm{NS}}$ & $13.42 \pm 0.42$ & $14.45 \pm 0.41$ & $14.26 \pm 0.28$ & \\
\hline
\end{tabular}

NS - Non-significant 